\title{
Inulin Clearance
}

National Cancer Institute

\section{Source}

National Cancer Institute. Inulin Clearance. NCI Thesaurus. Code C98748.

The rate at which inulin is removed or cleared from the whole or part of the body. 